\title{
O tradutor em cena
}

\section{The Translator on Stage}

\author{
Márcia Atálla Pietroluongo
}

\begin{abstract}
Preliminary reflections, based on the works by Michel Pêcheux and Michel Foucault on a certain place occupied by the translator whose subjective position stages a public scene of knowledge and power. Between the public and the private spheres, such place as executed in witness thereof assigns to each document the character of a monument, producing unique effects of meaning, and outlining a proper space of identity constitution.
\end{abstract}

Key words: certified translation, knowledge-power, translator's position.

Resumo: Reflexões preliminares, fundamentadas nas obras de Michel Pêcheux e Michel Foucault, sobre um certo lugar tradutor cuja posição subjetiva instaura uma cena pública de saber e de poder. Entre o público e o privado, este lugar assinado de verdade e fé atribui a cada documento o caráter de um monumento, produzindo efeitos singulares de sentido e delineando um espaço próprio de constituição de identidade.

Palavras-chave: Tradução pública; Saber-poder; posição tradutiva.

\footnotetext{
Professora Associada do Programa de Pós-Graduação em Letras Neolatinas da Universidade Federal do Rio de Janeiro e Tradutora Pública e Intérprete Comercial. E-mail: pietromarcia@gmail.com.
} 
Pietroluongo, M. A. - O tradutor em cena

No âmbito de uma reflexão que se inscreve em questões de Tradução, Ética, e Subjetividade, visando a explorar a situação particular em que o tradutor se envolve deliberadamente em seu trabalho, ganhando enorme visibilidade e devendo responsabilizar-se por sua assinatura pelos efeitos de sua tradução na sociedade, vou apresentar aqui um quadro singular a que intitulo $O$ tradutor em cena, título que deve ser ouvido nas duas dimensões do significante, como o tradutor em cena, mas também como o tradutor encena.

Para tanto, vou me centrar no caso particular de uma cena tradutória onde o ideal de imparcialidade e de distanciamento em relação ao texto traduzido é igualmente valorizado, mas agora sob a égide de uma enorme visibilidade do tradutor, e de uma tradução que só se sustenta por ser assinada. Trata-se de um tipo específico de tradução que só ganha legitimidade por essa assinatura que efetivamente obriga o tradutor a se responsabilizar pelos efeitos do texto traduzido na sociedade.

Para facilitar nosso entendimento das questões com que vou trabalhar, escolhi uma lauda de tradução em português, embora esse aparato enunciativo-discursivo exista também no formato de lauda para versão nas diferentes línguas estrangeiras. Mais precisamente tenho como objeto de reflexão a posição subjetiva do Tradutor Público no campo dos Estudos da Tradução, como objeto de análise o discurso do tradutor, e como unidade de análise sua lauda, a textualização de seu discurso.

Essas reflexões se inscrevem numa confluência entre a Análise do Discurso de escola francesa, notadamente teorizada por Michel Pêcheux, e a arqueologia e a genealogia de Michel Foucault, enfatizando um certo lugar tradutor cuja posição subjetiva instaura uma cena pública de saber e de poder. Entre o público e o privado, este lugar assinado de verdade e fé atribui a cada documento o caráter de um monumento, produzindo efeitos singulares de sentido e delineando um espaço próprio de constituição de identidade.

Segundo Michel Foucault (1969: 13-15), a história memorizava os monumentos do passado, transformando-os em documentos. Na tentativa de restituir o passado de que eram vestígio, estes eram interrogados para se examinar sua autenticidade e veracidade. Numa mudança de perspectiva, 
Pietroluongo, M. A. - O tradutor em cena

salientada pelo filósofo, a história passa não mais a ter como objeto primeiro interpretá-los, doravante ela transforma os documentos em monumentos, isolando os elementos, agrupando-os, verificando sua pertinência, estabelecendo relações, constituindo conjuntos.

Meu objetivo primeiro aqui é examinar essa monumentalização do documento constituído por essa lauda, refletindo, ainda preliminarmente, sobre esse lugar tão particular do Tradutor Público, geralmente conhecido como Tradutor Juramentado, no campo dos Estudos da Tradução. Vamos ressaltar algumas das características do ofício do TP importantes para se entender as condições de produção desse lugar.

Segundo Michel PÊCHEUX (1969), as condições de produção são definidas como circunstância de um dado discurso em que estão em jogo três elementos básicos: o lugar que o sujeito ocupa; a relação de forças entre os sujeitos, e as relações de sentido, uma vez que todo discurso está sempre vinculado a discursos que the são anteriores, simultâneos ou posteriores.

Devidamente concursado e habilitado pela Junta Comercial de seu Estado, o tradutor público presta juramento de que desempenhará suas funções dentro da ética e do sigilo profissionais, traduzindo fielmente o teor dos documentos que the são apresentados. Todo documento por ele traduzido para o idioma vernáculo passa a ter validade legal, produzindo efeito em todo território nacional junto a repartições públicas da União, Estados e Municípios, assim como em todos os Juízos, Tribunais ou entidades ligadas ao poder público. Por outro lado, suas versões para o idioma estrangeiro também são reconhecidas pela maioria dos países, alguns deles exigindo, entretanto, legalização da assinatura do tradutor junto a seus respectivos consulados.

Seu ofício pessoal e intransferível é regido por decretos e instruções normativas, atribuindo-lhe um lugar bem determinado no campo. Sua tradução tem fé pública, ou seja, a ela é atribuída credibilidade inconteste e certeza de verdade, uma vez que a fé pública é o crédito que a lei confere aos atos de um oficial público. Trata-se, portanto, de tradução pessoal, assinada e com a validade legal de um documento oficial. 
Pietroluongo, M. A. - O tradutor em cena

Uma característica peculiar desse tipo de tradução é a duplicidade documental. Toda tradução pública é obrigatoriamente acompanhada do documento original devidamente carimbado com o número e ano da tradução a que corresponde. Disso resulta um caráter sui generis que a diferencia de todos os outros tipos de tradução: a tradução pública não tem o estatuto de um substituto do documento original, mas é antes um instrumento de inteligibilidade, de legibilidade de um documento estrangeiro perante a administração e os poderes públicos nacionais.

A lauda do tradutor público funciona como uma teatralização, uma encenação ao longo da qual o tradutor-narrador dá a palavra a diferentes atores, restituindo o conteúdo do documento que the fora apresentado em outra língua.

Sob o termo genérico de tradução/versão, coexistem vários tipos de textos e discursos traduzidos/vertidos, de uma simples carta a uma ata de sociedade empresarial, de um documento extraído da internet a uma ação de alimentos. Do ponto de vista da tipologia, o discurso público traduzido abrange necessariamente textualizações muito diversificadas e heterogêneas e compreende uma vasta gama de discursos incorporados. O que thes delimita a configuração é a finalidade do contratante que precisa apresentar aquele documento a algum poder público em esfera nacional ou internacional.

A lauda do tradutor público é, assim, uma mise-en-scène: um aparato enunciativo-discursivo que tem uma apresentação mais ou menos homogênea com um cabeçalho com dados do profissional e um termo de abertura e outro de fechamento, no qual o tradutor toma obrigatoriamente a palavra, como podemos ver abaixo: 
Pietroluongo, M. A. - O tradutor em cena

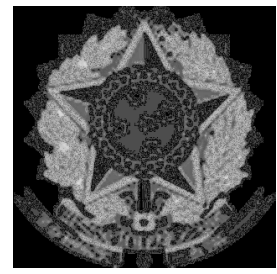

XXX da Silva

TRADUTOR Público E INTÉRPRETE COMERCIAL JURAMENTADO

IDIOMA XXXX-PORTUGUÊS

Membro da Associação Profissional de Tradutores Públicos e Intérpretes Comerciais, Juramentados, do Estado de XXXX

TRADUÇÃO N XX/ANO X

Eu, abaixo assinado, Tradutor Público e Intérprete Comercial Juramentado, matriculado sob o $\mathrm{n}^{\circ} \mathrm{xxx}$ na Junta Comercial do Estado de xxxx, República Federativa do Brasil, CPF $\mathrm{n}^{\circ} \mathrm{xxxxx}$, declaro que me foi apresentado 0 documento abaixo indicado, exarado no idioma $x x x x x$, a fim de que o traduza para o vernáculo, o que cumpro em razão de meu ofício.

TEXTO TRADUZIDO

É O QUE CONSTAVA do referido documento ao qual me reporto e, por ser verdade, DOU FÉ.-

POR TRADUÇÃO CONFORME.

Feita em (estado, dia - mês - ano).

Emolumentos: $\mathrm{R} \$ \mathrm{xxx}-\mathrm{xx}$ dias úteis. 
Pietroluongo, M. A. - O tradutor em cena

Seguindo esse princípio de monumentalização do documento traduzido, a lauda do tradutor público cunha marcas de autenticidade e de regularidade: 1. A tradução pública é um ato autêntico, ela traz indicações em seu texto dos elementos que a tornam autêntica: indicação de data e de lugar com precisões que fazem dela um documento histórico.

2. O cabeçalho da tradução contém a indicação do tradutor juramentado, representante da Junta Comercial, seus dados pessoais e institucionais. 0 autor da tradução é, assim, designado tanto sob a insígnia pessoal quanto institucional, a tradução indicando a que Junta Comercial ele se afilia.

3. Como já dito anteriormente, a tradução só é válida quando assinada e quando acompanhada do documento original devidamente carimbado e numerado ( $n^{\circ}$ da tradução e ano).

4. Essas indicações não são meros complementos exteriores ao corpo do texto. Elas se configuram como um discurso sobre o discurso.

5. Uma vez que a tradução esteja finalizada, o tradutor público se volta para ela para apresentá-la. Esse procedimento de retorno aparece claramente na fórmula que precede diretamente sua assinatura no final da tradução: Feita em (lugar) na (data)...

6. Essa formatação da tradução em boa e devida forma, para servir e valer a todos os fins de direito, para gozo de todos os direitos e prerrogativas legais, dá um cunho de atestação, de discurso atestatório ao discurso principal, o corpo propriamente dito da tradução.

7. Tudo isto está a serviço da monumentalização do ofício do tradutor.

8. As marcas de autenticidade estão a serviço da atestação da regularidade da tradução, enquanto documento público oficial, pois, permitem à jurisdição de controle, à Junta Comercial a que se afilia o tradutor, verificar a regularidade formal da tradução.

9. Essas indicações pertencem à aparelhagem do discurso tradutório. Elas o acompanham e o envolvem para apresentá-lo nas circunstâncias que envolveram seu desenrolar. Trata-se de um discurso tecido sobre o discurso principal, a tradução propriamente dita. Elas funcionam, de alguma forma, 
Pietroluongo, M. A. - O tradutor em cena

como um comentário deste discurso. Trata-se de uma metalinguagem em que o tradutor se descreve traduzindo.

10. O documento constituído pela tradução pública traz, assim, os meios de verificação de sua regularidade, permitindo reconstituir a encenação, cujo ato final é a tradução.

Nesta perspectiva, a lauda configura-se como um palco e a tradução propriamente dita constitui a peça que ali foi encenada. Em sua tradução, o tradutor publica o nome dos atores em sua distribuição de papéis: notários, escreventes, escrivães, tabeliães, advogados, sócios de um empreendimento, reitores, diretores de estabelecimento de ensino, entre muitos outros. Portanto, toda tradução contém o equivalente de um programa de teatro, ou os créditos, a ficha técnica de um filme. A indicação dos papéis e dos atores une o caráter institucional e o caráter pessoal no texto da tradução.

Vou me centrar agora nas figuras de sujeito que ressaltam dessa lauda. Como reitera Eni ORLANDI (1988: 61), a partir de Oswald Ducrot e de Michel Foucault, três são as funções enunciativas do sujeito. Aquele que se representa como EU no discurso é o locutor. 0 ponto de vista tomado por esse EU é o enunciador. E o autor é a função social assumida por esse EU enquanto produtor da linguagem. "O autor é, das dimensões enunciativas do sujeito, a que está mais determinada pela exterioridade (contexto sócio-histórico) e mais afetada pelas exigências de coerência, não-contradição, responsabilidade, etc."

Ao nível do enunciado, há a presença de um locutor, de um EU que toma a palavra para enunciar uma verdade sobre algo, sobre alguém. EU que conta uma história pessoal e/ou institucional, a história de um documento comercial, jurídico, mas também a verdade de um sujeito (seus casamentos, divórcios, os filhos que nascem, os óbitos em sua família, entre vários outros).

EU que se ocupa, portanto, do anúncio da verdade de um documento, tal como esta se dá a ler no documento original ${ }^{1}$. EU que se verifica a partir

\footnotetext{
${ }^{1}$ Não se trata aqui, evidentemente, de aceitação, aprovação ou adesão ao teor do documento pelo tradutor público, mas simplesmente de apresentá-lo em sua "verdade redigida".
} 
Pietroluongo, M. A. - O tradutor em cena

de marcas pessoais de identificação e de marcas institucionais. Trata-se da imagem textualizada de uma "pessoa pública".

Nunca é demais lembrar que não estamos aqui diante da figura de um Tradutor Juramentado, pessoa física, figura do mundo biossocial, mas diante de imagens construídas da subjetividade desse tradutor. Nossa análise se centra nessa construção enunciativo-discursiva desse sujeito de papel, que não se confundiria com nenhuma realidade empírica.

Entretanto, mesmo não se tratando das mesmas instâncias, é evidente que há todo um jogo de espelhos, de espelhamentos entre um e outro, com visadas muito claras no sentido de dar credibilidade e legitimidade a esse discurso. Estamos aqui diante das instâncias de saber-poder exaustivamente trabalhadas por Michel Foucault em sua obra.

Sendo um ato oficial (POR TRADUÇÃO CONFORME), a tradução pública é um ato de autoridade que emana de um tradutor investido de saber-poder e do dever de contar a história daquele documento. 0 tradutor fala em nome próprio, mas sempre sustentado pela Instituição, Jurisdição Comercial que the dá estofo.

Esquematicamente, podemos afirmar que a partir da análise de sua lauda, o tradutor público se apresenta como um locutor que afirma uma verdade sobre algo, sobre alguém. Num certo sentido, um locutor-narrador que conta uma história pessoal e/ou institucional.

Como enunciador, a perspectiva, o ponto de vista por ele tomado é impregnado de grande autoridade para validar e dar cunho de verdade ao documento traduzido. Podemos, portanto, afirmar que, ao monumentalizar a lauda enquanto documento, ele monumentaliza, assim, seu lugar enquanto tradutor, forjando para si um lugar de grande prestígio, atribuindo-se saberes e poderes particulares num campo onde o tradutor é, tantas vezes, percebido com menos valia.

Como autor da tradução por ele assinada, e que só se sustenta por essa assinatura, ele funciona como um foco, princípio de agrupamento de uma heterogeneidade de discursos, textualizando-os, e assegurando ao documento traduzido um imaginário de unidade e coerência. 
Pietroluongo, M. A. - O tradutor em cena

Ressalta-se que estamos aqui muito distanciados daquele imaginário clássico do tradutor melancólico, invisível e desprestigiado. Porém, gostaria de salientar mais uma vez que estou examinando um imaginário textualizado do tradutor, não subscrevendo absolutamente a qualquer aderência deste a qualquer figura de pessoa física num dito "mundo real".

Destaco ainda que, tanto em Pêcheux quanto em Foucault, estamos no âmbito de concepções não subjetivas de enunciação, de concepções objetivadas de sujeito, o sujeito sendo efeito de uma objetivação. $\mathrm{Na}$ perspectiva foucaultiana, o sujeito é pensado como um objeto historicamente constituído a partir de determinações que the são externas, não se configurando como sujeito consciente, livre e a-histórico da tradição filosófica.

Para PÊCHEUX (1993: 164) igualmente: "Todo indivíduo é transformado em sujeito ideológico e 'conduzido, sem se dar conta, e tendo a impressão de estar exercendo sua livre vontade, a ocupar seu lugar'”. Reconhecimento e desconhecimento são os operadores a partir dos quais a ideologia funda os efeitos de evidência do sujeito e do sentido.

A enunciação não é, portanto, entendida aqui como tomada de palavra de um sujeito que exerce sua vontade de expressão, que é dono de seu dizer. Nessa perspectiva, há um descentramento da noção de sujeito que está submetido ao caráter material e à historicidade dos processos de significação.

Discurso aqui é entendido como prática, lugar onde sujeito e sentido são constituídos, atravessados pela interpelação ideológica. As duas grandes ilusões, os dois grandes efeitos de evidência forjados pela ideologia, segundo Michel Pêcheux, a de um sentido único, que não poderia ser outro, o sujeito dizendo exatamente aquilo que quer dizer; e a de um sujeito como fonte, origem de seu dizer, comparecem regiamente nesse imaginário monumentalizado na lauda do tradutor público.

Concluindo, podemos afirmar que a lauda é um exercício de monumentalização da tradução enquanto ofício e do lugar de poder-saber do tradutor público dentro do campo dos Estudos da Tradução. 


\section{Referências bibliográficas}

CORNU, Gérard. Linguistique juridique. Paris: Montchrestien, 1990.

Foucault, Michel. L'archéologie du savoir. Paris:Gallimard, 1969.

ORLANDI, Eni P. Discurso e leitura. Campinas: Cortez/Editora da Unicamp, 1988.

PeCheuX, Michel. Analyse automatique du discours. Paris: Dunod, 1969.

PeCheux, Michel; Fuchs, Catherine. A propósito da Análise Automática do Discurso : atualização e perspectivas. Tradução de Péricles Cunha. In : GADET, Françoise ; HAK, Tony. (orgs). Por uma análise automática do discurso: uma introdução à obra de Michel Pêcheux. Campinas: Unicamp, 1993. p. 163-252. Tradução de: Mises au point et perspectives à propos de l'analyse automatique du discours, 1975.

PeCheux, Michel. . L'inquiétude du discours, textes de M. Pêcheux choisis et présentés par D. Maldidier. Paris: Éditions des Cendres, 1990. 